\title{
A study of help seeking behavior of psychiatric patients
}

Pradhan SN', Sharma SC ${ }^{2}$, Malla DP³ ${ }^{3}$ Sharma R ${ }^{3}$

${ }^{1}$ Associate Professor, ${ }^{2}$ Assistant Professor, ${ }^{3}$ Lecturer, Department of Psychiatry

Kathmandu Medical College, Sinamangal, Kathmandu, Nepal

\section{Abstract}

Background: A large number of mentally ill patients prefer to visit non-medical practitioners such as faith healers because of the stigma attached to mental illness and/or belief that mental illness are caused by supernatural powers. Faith healers are more convenient to be approached first because of ease of availability and prevalent cultural belief and persuasion. Objective: The current study aims to find the help seeking behavior of patients suffering from mental illness and whom they approach first once affected, either psychiatrists or faith healers.

Methods: A cross sectional study was conducted among patients admitted in the psychiatric ward of Kathmandu Medical College Teaching Hospital during 1st January to $30^{\text {th }}$ July 2012. All patients admitted in the ward during that period were informed about the purpose of the study and a written informed consent was taken. In case of psychotic patients, the consent was obtained from nearby relatives.

Results: Among 54 patients enrolled in the study, significant number of psychotic patients $(n=15)$ visited faith healers in comparison to only 4 non-psychotic patients. Number of females $(n=12)$ visiting faith healers in comparison to males $(n=7)$ was higher. Patients having belief in black magic were more likely to visit faith healers than those who were nonbelievers.

In contrary to the popular belief, patients approaching the faith healers spent more money $(>\$ 20)$ in the treatment than who approached psychiatrists $(<\$ 20)$.

Conclusion: The study shows that most of the patients suffering from mental illness prefer to approach faith healers first because of the prevailing trust on faith healers, because they are locally available and because of a prevailing belief in supernatural causation of mental illness.

Key words: Help seeking behaviour, Psychiatric Disorders, Traditional faith healers

\section{INTRODUCTION}

A large number of patients suffering from mental disorders seek nonprofessional care such as traditional faith healers and practitioners of alternative systems of medicine such as Ayurveda'.

In a developing country like Nepal majority of people live in rural areas. Psychiatric facilities are however, located mainly in major cities. In this context most of the people suffering from mental disorders do not have access to hospitals and generally approach traditional faith healers. This is because they are easily accessible and locally available. Most importantly people living in rural areas have been contacting them for ailments

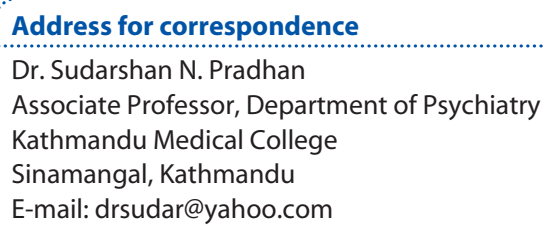

from centuries and have developed a strong sense of trust and belief that faith healers can cure their ailments. Moreover, faith healers provide culturally sensitive care. For these reasons faith healers play a crucial role in the care of people with mental disorders as well in the developing world ${ }^{2}$.

Psychiatric illnesses are often associated with social stigma, forcing families to hide the problems and avoid psychiatric treatment. In South Asian countries a handful of patients with psychiatric disorders receive professional treatment and the majority of them are forced to hide their ailments even though it is causing substantial distress and role impairment ${ }^{3,4}$. It is seen that large number of patients instead approach the easily accessible people such as traditional faith healers who they are closely attached to and have confidential relationship with and believe that their illnesses will not be revealed to others along with a strong belief in the supernatural causation of mental illness and that these 
can be effectively handled by faith healer and their treatment.

In India traditional healers and religious people play an important role in providing service for patients with mental illness. This population are as high as up to three quarters of the mentally affected population $5,6,7,8,9$.

The current study aims at exploring and comparing patients with mental illness who attend faith healers, and others who attend psychiatrists in terms of their socio-demographic profile and the type of mental illnesses they are suffering from.

\section{METHODS}

This is a cross-sectional study carried out in patients who were admitted in the psychiatric ward of Kathmandu Medical College Teaching Hospital during 1st January to $30^{\text {th }}$ July 2012 . All the patients who were admitted in the wards were informed about the purpose of the study and written informed consent were taken. Patients who did not give the consent were excluded from the study. In case of psychotic patients, the information were obtained from nearby relatives.

A semi-structured proforma was used for information into socio-demographic data and diagnoses according to International Classification of Diseases - 10 (ICD-10). All data were entered and analyzed with SPSS 16.5 .

\section{RESULTS}

Altogether 54 patients were enrolled in the study (Table 1). Twenty nine (53.7\%) were male and 25 (46.3\%) were female. Among these, 27 (50\%) were married and 27 (50\%) were unmarried. According to the two diagnostic groups 26 (48.1\%) were psychotic patients (Schizophrenia $30.7 \%$, Bipolar affective disorder 46.1 $\%$, Acute psychosis $23.1 \%$ ) and 28 were non-psychotic patients (Depressive disorder 46.4\%, Anxiety disorder $7.14 \%$, Conversion disorder $10.7 \%$, Alcohol dependence $35.7 \%)$. Forty six (85.2\%) were literate and 8 (14.8\%) were illiterate. Twenty two (40.7\%) patients believed in Black magic and 32 (59.3\%) were non-believers.

Results show that a total of $64.8 \%$ visited Psychiatrists first and $35.2 \%$ visited faith healers. According to diagnostic entity, $57.7 \%$ of psychotic patients went to faith healers as compared to non-psychotic patients (14.3\%). This distribution was statistically significant at .001 level. Belief in black magic was another factor which determined whether patients approached faith healers or medical doctors in a statistically significant way. Among the 22 believers, $77.3 \%$ visited faith healers in comparison to $6.25 \%$ non-believers. In terms of spending, patients approaching faith healers actually were spending more money than who approached a psychiatrist. Among all the patients visiting a faith healer first $84.2 \%$ (16 out of 19) spent more than $\$ 20$ in comparison to only $31.4 \%$ (11 out of 35 ) visiting a psychiatrist spent more than $\$ 20$.

As shown in Table 2, majority of psychotic patients $(57.7 \%)$ visited faith healers whereas only $14.3 \%$ of nonpsychotic category visited them. This distribution as shown in Table 1 is statistically significant at .001 level. Majority of patients, 24 (85.7\%) of the non-psychotic category visited medical doctors in comparison to only 4 (14.3\%) from this category visited Faith healers.

All patients suffering from Acute psychosis visited faith healers whereas 3 out of $8(37.5 \%)$ patients with Schizophrenia and 6 out of 12 (50\%) of Bipolar Affective Disorder (BPAD) patients visited Faith healers.

Table 1: Various factors according to first visit to Faith healers or Psychiatrist

\begin{tabular}{|c|c|c|c|c|c|}
\hline & \multicolumn{4}{|c|}{ Whom did you contact first } & \multirow{3}{*}{ p-value } \\
\hline & \multicolumn{2}{|c|}{ Faith healers } & \multicolumn{2}{|c|}{ Psychiatrist } & \\
\hline & $\mathbf{n}$ & $\begin{array}{l}\% \text { of } \\
\text { total }\end{array}$ & $\mathbf{n}$ & $\begin{array}{l}\% \text { of } \\
\text { total }\end{array}$ & \\
\hline \multicolumn{6}{|l|}{ Diagnosis } \\
\hline Psychotic & 15 & 27.8 & 11 & 20.4 & \multirow{2}{*}{.001} \\
\hline Non-psychotic & 4 & 7.4 & 24 & 44.4 & \\
\hline \multicolumn{6}{|l|}{ Gender } \\
\hline Male & 7 & 13.0 & 22 & 40.7 & \multirow{2}{*}{.061} \\
\hline Female & 12 & 22.2 & 13 & 24.1 & \\
\hline \multicolumn{6}{|l|}{ Marital Status } \\
\hline Married & 10 & 18.5 & 17 & 31.5 & \multirow{2}{*}{.500} \\
\hline Single & 9 & 16.7 & 18 & 33.3 & \\
\hline \multicolumn{6}{|l|}{ Education } \\
\hline Literate & 16 & 29.6 & 30 & 55.6 & \multirow{2}{*}{.588} \\
\hline Illiterate & 3 & 5.6 & 5 & 9.3 & \\
\hline \multicolumn{6}{|l|}{$\begin{array}{l}\text { Belief in Black } \\
\text { Magic }\end{array}$} \\
\hline Yes & 17 & 31.5 & 5 & 9.2 & \multirow[t]{2}{*}{.000} \\
\hline No & 2 & 3.7 & 30 & 55.6 & \\
\hline \multicolumn{6}{|l|}{ Total spending } \\
\hline$<\$ 20$ & 3 & 5.6 & 24 & 44.4 & \multirow{2}{*}{.000} \\
\hline$>\$ 20$ & 16 & 29.6 & 11 & 20.4 & \\
\hline
\end{tabular}


Table 2: Diagnostic categories visiting Faith healers or Psychiatrist

\begin{tabular}{|c|c|c|c|c|}
\hline & \multicolumn{4}{|c|}{ Whom did you contact first } \\
\hline & \multicolumn{2}{|c|}{ Faith healers } & \multicolumn{2}{|c|}{ Psychiatrist } \\
\hline & $\mathbf{N}$ & $\begin{array}{l}\% \text { of non- } \\
\text { psychotic } \\
\text { patients }\end{array}$ & $\mathbf{N}$ & $\%$ \\
\hline \multicolumn{5}{|l|}{$\begin{array}{l}\text { Non-psychotic } \\
\text { Disorders }\end{array}$} \\
\hline Depression & 4 & 14.3 & 9 & 32.1 \\
\hline Anxiety & 0 & 0 & 2 & 7.2 \\
\hline Conversion Disorder & 0 & 0 & 3 & 10.7 \\
\hline Alcohol Dependence & 0 & 0 & 10 & 35.7 \\
\hline Psychotic disorders & & $\begin{array}{c}\% \text { of } \\
\text { psychotic } \\
\text { patients }\end{array}$ & & \\
\hline Acute Psychosis & 6 & 23.1 & 0 & 0.0 \\
\hline Schizophrenia & 3 & 11.5 & 5 & 19.2 \\
\hline $\begin{array}{l}\text { Bipolar Affective } \\
\text { Disorder }\end{array}$ & 6 & 23.1 & 6 & 23.1 \\
\hline
\end{tabular}

\section{DISCUSSION}

The study shows that $35.2 \%$ of the patients with psychiatric disorders visited faith healers as a first contact in comparison to the psychiatrist. This large group of patients usually visit the traditional faith healers because they are easily approachable and also because they have belief in supernatural cause of mental disorder as well as because of recommendations of relatives and friends. This study is consistence with the earlier research done in India 710,11 , 12, which found a significantly higher consultation rate with faith healers in those patients with schizophrenia and delusional disorders. In the current study those patients with psychotic illnesses usually went to faith healers because of the strong belief in faith healers and a belief in black magic as well as in the concept of possession by God.

Many patients and their care takers usually give priority to the alternative service providers such as traditional faith healers, astrologers and ayurveds ${ }^{13}$, ${ }^{14}$. They approach such groups because of lack of awareness or the absence of easily accessible treatment facilities especially in developing countries like Nepal, where transportation of medical facilities are scarce in rural areas and the psychiatric facilities are available only at general hospitals and mental hospitals. In the urban areas as well, psychiatrists are preferred as a least priority due to stigma. Psychiatric illnesses are often accompanied by social stigma, leading to more suffering from severe mental disorders and subsequently families try to hide the illness and avoid psychiatric treatment ${ }^{11}$. This is also another reason to seek help from traditional faith healers.

In the current study majority of people believing in black magic (40.7\%) sought help from the traditional healers. In comparison to this group those who did not believe in black magic sought help from psychiatrist. This finding is consistent with the study done in India. ${ }^{15}$ The similarity of these findings is probably due to the cultural resemblance in these two countries.

It has generally been thought that most of the patients seek help from traditional healers because they believe that these healers are cost effective. In contrast, the current study shows that this is not true. Among all patients visiting a faith healer first $84.2 \%$ (16 out of 19) spent more than $\$ 20$ in comparison to only $31.4 \%$ (11 out of 35 ) visiting a psychiatrist spent more than $\$ 20$. The cost eventually rises as people are made to spend money in many different ways such as consultation charges, sacrifices of goat or cock to the God, buying the "Jantra" or "Tabiz", offering special worships (Puja) to the God, sacrificing pigeons and / or freeing the pigeons in the sky, etc.

The present study shows that more females approached the traditional healers than males, and males tended to approach psychiatrist more than females. This finding is similar with earlier research done in India ${ }^{16}$.

These findings also might be due to the level of education which is high in males in comparison to females.

\section{CONCLUSION}

This study reveals that the trend of first contact of mentally ill patient to the faith healer is quite common. Therefore it is highly recommended that there is a need for awareness programs to the faith healers so that they are better able to recognize the severity of mental illness and to subsequently refer these cases to the psychiatrist in time. Moreover easy access of service is one important factor in the decision as to whom patients approach first which highlights the necessity of making psychiatric care more easily accessible in rural areas. 


\section{REFERENCES}

1. Patel V, Simunyu E, Gwanzura F. The pathways to primary mental health care in high-density suburbs in Harare, Zimbabwe. SocPsychiatry Psychiatri Epidemiol.1997; 32 (2): 97-103.

2. Gater R, De Almeida E, Sousa B, Barrientod G, Caraveo J, Chandrasekhar CR et al. The pathways to psychiatric care: a cross cultural study. Psychol Med. 1991; 21: 761-74.

3. Wells KB, Manning WJR, Benjamin B. A comparison of the effects of sociodemographic factors and health status on use of outpatients mental health services in HMO and fee-for-service plans. Medical Care.1986; 24: 949-60.

4. Katz SJ, Kessler RC, Frank RG, Leaf PJ, Lin E, EdlundEJ. The use of outpatient mental health services in the United States and Ontario: The impact of mental morbidity and perceived need for care. Am J of Public health. 1997: 87; 1136-43.

5. Pradhan SC, Singh MM, Singh RA, Das J, Ram D, Patil $B$, et al. First care giver of mentally ill patients: multicentre study. Indian J Med Sci. 2001; 65: 203-8.

6. Raghuram R, Venkateswaran A, Ramkrishna J, Weiss MG. Traditional community researches for mental health: a report of temple healing from India. BMJ. 2002; 325: 38-40.

7. Campion J, Bhugra D. Experiences of religious healing in psychiatric patients in South India. Soc Psychiatry PsychiatrEpidemiol. 1997; 32: 215-21.
8. Janakirmaiha N, Badrinath B, Channavasavanna SM, KaliaperumalVG. Dealing with deviant behavior. Indian J Psychiatry. 1979; 21: 206-10.

9. NagpalSJS, Mishra N, Chadda RK, Sood M, Garg R. Changing trends of services used as first contact by patients with mental health problems. National Med J India. 2011; 24(3): 148-50.

10. Chadda RK, Agrawal V, singhMC, Raheja D. Help seeking behavior of psychiatric patients before seeking care at a mental hospital.Int J Soc Psychiatry. 2001; 47: 471-8.

11. Bhattacharya DP. Psychiatric pluralism in Bengal India. SocSci Med. 1983;17: 947-56.

12. Mohamed OS, Bader S, Said Y, sufyan S. Help seeking behavior of patients attending the psychiatric service in a sample of United Arab Emirates population. Int J Soc Psychiatry. 2009; 55: 141-8.

13. Nunley M. The involvement of family in Indian Psychiatry. Culture Med Psychiatry. 1998; 22: 317-53.

14. Weiss M, Desai A, Jadhav S, Gupta L, ChannabasavannaSH, Doongaji DR, et al. Humoral concepts of mental illness in India. SocSci Med. 1998;27: 471-7.

15. Ravishankar B, Saravanan B, Jacob KS. Explanatory models of common mental disorders among traditional healers and their patients in rural South India. Int J Soc Psychiatry. 2006; 52: 221-33.

16. Kapur RL. The role of traditional healers in mental health care in rural India. SocSci Med. 1979;13: 27-31. 